\title{
5.2 Directions of ecologization of oil and fat industry enterprises
}

The oil and fat industry of Ukraine is one of the branches of the food complex, which consists of interconnected production of oil, fats, margarine, edible oil and sales. As a raw material, the oil and fat industry uses oilseeds: sunflower, soybean, rapeseed, flax, peanuts, hemp, etc. The seeds of these crops contain an average of 35-40, and in the best varieties - more than $50 \%$ oil. And in macus and sprat and most of them contain $30-35 \%$ protein and up to $10 \%$ oil, which makes them a concentrated high-value animal feed. In a relatively short period of time, the oil and fat complex of Ukraine has significantly restored and increased its production potential. Ukraine is the largest producer of sunflower oil in the world, its share in world production is $23 \%$, and the share of exports is $51 \%$. But Ukraine has gained the status of a leader in the production of unrefined sunflower oil in the world relatively recently. To stimulate the growth of sunflower oil production in Ukraine, an export duty on sunflower seeds was introduced.

For the proper and active development of the agro-industrial complex, it is necessary to support the active mutual development of the state and business. Among the main tasks for both structures should be, first, to improve the existing legislation in order to adapt as easily as possible to the global principles of corporate governance. Second, international standards must be introduced on a mandatory basis, not voluntary ones, and compliance with them must be clearly monitored. Particular attention should be paid to creating preconditions for institutional support, agrarian business, development of agricultural advisory system in the form of information and consulting assistance to agricultural producers and rural population, development of small-scale agricultural production, agricultural cooperation to ensure integration of personal farms into the market. [171].

The main problems of the oil and fat industry are as follows. High level of monopolization of the industry. Thus, the industry is represented by more than 1.2 thousand enterprises, but the nine largest companies in 2013 accounted for $85 \%$ of production of unrefined sunflower oil, $66 \%$ of production of refined sunflower oil and $82 \%$ of production of margarine products from the corresponding volumes of their total 
production in Ukraine. Another consequence of the monopolization of the oil and fat industry is the underutilization of production capacity of enterprises, due to the logical desire of large enterprises to use their monopoly power - to produce and sell even a smaller amount of products, but at a higher price.

Insufficient innovation and investment orientation of oil and fat enterprises. At first glance, the oil and fat industry is one of the most innovation-oriented sectors of the domestic economy. The innovative activity of the enterprises of the oil and fat industry is carried out through the introduction of complex equipment to ensure the full cycle of production of oil and derived products; application of new types of catalysts in oil and fat production technologies; improvement of oil extraction technology and margarine production; use of waste oil and fat production to create new products.

Poorly developed system of storage and transportation of oil and fat products in Ukraine. The development of the storage system in Ukraine is carried out through storage in agro-holdings, storage in small and medium-sized agricultural producers, the development of port and river grain terminals. The basis of the storage system are elevators of different types, which are a set of structures and mechanisms designed to receive grain, its post-harvest processing (cleaning, drying), storage and shipment to various modes of transport, however, the current system of storage of oil products in Ukraine does not meet modern requirements globalization space and the existing export orientation of the industry. The latter is confirmed by the fact that despite the investment orientation of the industry, the construction of the storage system remains the prerogative of large enterprises and is almost unattainable for medium and small enterprises in the industry in the absolute absence of state support in this area.

The highest growth rate of production and exports in the world is due to soybean oil. Thus, the production of sunflower oil from 15.45 million tons in 2019 increased to 17.72 million tons in 2019, an increase of $114 \%$. In turn, palm and soybean oil showed an increase of 117 and $123 \%$, respectively. Palm oil is cheap to produce because it provides 5-8 times higher yields than other oil sources, and palm tree does not require special care. Of course, in contrast to sunflower and soybeans, the care and nutrition of which will directly affect the quantity and quality of the final product [172]. 
In Ukraine, the production of oilseeds accounts for a large share of crops grown in general. Of the almost 95 million tons of crops grown in the 2018-2019 marketing year, more than 22 million tons fell on soybeans, soybeans and rapeseed together. This figure is growing every year. Soybean processing capacity reached 5.44 million tons per year, rapeseed - more than 2 million tons per year.

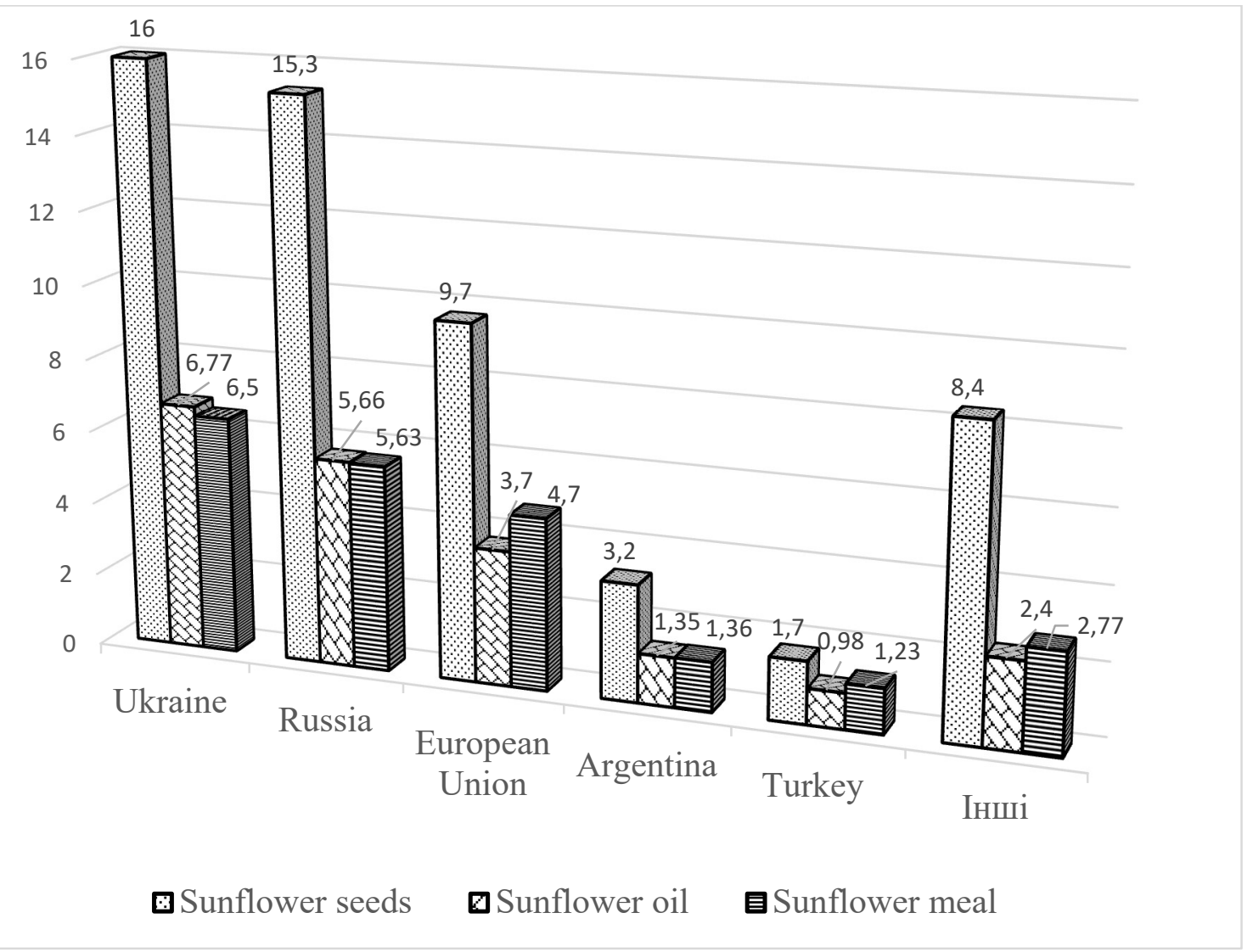

Fig. 5.2.1 The largest producers of sunflower, oil and meal in the world, million tons Source: constructed by the author according to [173]

However, due to mass exports of soybeans and rapeseed, they are loaded by only $16 \%$, despite the fact that Ukrainian-produced oil (soybean and rapeseed), as well as meal are in demand on the world market, especially in the EU. Our producers and exporters of oil and meal can satisfy all orders for their products in both domestic and foreign markets. In the 2018-2019 marketing year, 54.4 million tons of sunflower were harvested in the world, the leader was Ukraine, growing more than 15.5 million tons of this crop. In second place - Russia, collecting 15.3 tons, in third place - the EU, with a gross collection of 9.7 million tons.

The Organization for Economic Cooperation and Development in its forecast of 
agricultural development, sees the following trends for the next few years in the development of the market of vegetable oils: per capita consumption will continue to grow, the price will remain at 700-760 dollars. per metric ton, the growth in the use of vegetable oils in biodiesel will be quite slow. The main trend in the market of vegetable oils and oilseeds in the world is the growth of supply and this trend has been going on for more than ten years. In Ukraine, the oil and fat complex is developing similarly, domestic processing is growing, and exports are growing every year. In addition to the positive impact of increased foreign exchange earnings in the country and, there is another side to this process. World vegetable oil prices are falling and are currently at their lowest level in a decade.

Ukraine ranks first in the export of sunflower oil, placing about 6 million tons of products on foreign markets last marketing year. That is, of the total exports, 6.6 million tons of vegetable oils, 6 million tons - sunflower. Only 600,000 tons are other vegetable oils, despite the fact that processing capacity is underutilized by almost $30 \%$. Oilseed processing can be considered an almost waste-free production. For example, obtained in the process of aqueous hydration of oil (one of the types of refining) phosphatide concentrate has a high biological value and is used in the baking industry. The oil obtained in the process of extraction - extraction of oil from the cake or petals with a solvent, is used for the production of drying oils. Granulated sunflower husk is widely used in the world as an alternative fuel. Meal as a valuable biological additive is one of the components for the production of compound feeds for animal fattening.

The production base of enterprises allows to process different types of oilseeds: sunflower, rapeseed, soybeans, and the investment leads investors to pursue a prudent pricing policy for oilseeds, which encourages them to grow oilseeds. The outstripping increase in processing capacity causes fierce competition between processing enterprises in the domestic market of oilseeds and is a factor in maintaining the level of purchase prices for oilseeds. The oil market of Ukraine is one of the promising sectors of agricultural production. Oil products are in great demand on the world market due to two main factors: the growing reorientation in the structure of human nutrition to oils and fats of vegetable origin due to their physiological advantages and 
more affordable prices compared to animal fats and the dynamic growth of biodiesel production worldwide. based on vegetable oils against the background of progressive growth of prices for mineral energy resources and reduction of their natural reserves.

Today the issue of greening of production becomes especially important and relevant for all enterprises of the processing industry. Greening of production is understood as the expanded reproduction of natural resources through the introduction of new and improvement of existing technologies, optimization of the organization of material production, increasing labor efficiency in the field of environmental protection. The issue of environmental safety is now of paramount importance directly related to the preservation of human existence, as never before, the state of the environment is rapidly deteriorating due to the expansion of industrial production in all countries, as a result - it is important to constantly develop, improve and the implementation of strategies and models of greening of production, which is reflected in the environmental characteristics of the product of production, and, as a consequence, its competitive position in the market.

The introduction of ecological innovations will increase the efficiency of production, improve its ecological level, improve living conditions and human existence, which will be the basis for consolidating competitiveness through the greening of innovative development. Oil and fat industry - having a strong export potential, enterprises in this industry must also change the vector of work. This is primarily due to the significant depletion of natural resources, increasing anthropogenic impact and technological load on the environment. The need to green production is due to several important factors. The manufacture of products on obsolete equipment leads to the production of low-quality products, the accumulation of production waste, which creates the problem of utilization, reduced productivity, as well as too high resource and energy consumption [174].

Studies of a set of measures to prevent or stop the negative impact of economic processes on the environment, allow us to identify the main directions of greening of production, which coincide with the main applied tasks of eco-biotechnology.

1. Preparation and substantiation of effective solutions, methods and means for 
wastewater treatment from industry, rationalization of water resources of the country, reduction of emissions from stationary and mobile sources (industrial and transport). The implementation of these measures will help to prevent environmental pollution, of course, in part.

2. Measures aimed at reducing or completely eliminating hazardous waste that pollutes the environment are relevant and promising for implementation. The main direction recognized in the world is the transition to the use of closed technologies, a special feature of which is the lack of metabolism with the environment, ie, a process in which there are no emissions of solids, discharges of liquids and gases of gaseous waste. A promising direction here is the development of new, created on an alternative basis of technology in energy, new materials, possibly "nano-materials", the development of new technologies based on natural (environmental) processes, possibly the transition to biotechnology.

3. The principles of economics of nature generate such a modern direction of greening as recycling or reuse of waste. A separate type of reuse of the resource is the regeneration of primary waste. Regeneration is understood as additional processing of primary waste left in the production cycle and removal of compound elements that remained after that. The state of the environment largely depends on the creation and implementation of practical activities of effective mechanisms for managing industrial enterprises. Recently, a mechanism for improving production processes on the basis of greening is being developed. As the territory of Ukraine is recognized as a zone of ecological crisis, the solution of this issue is not only the need for integration into the European space, but, first of all, the goal is the physical survival of the population.

Achieving this, of course, as is generally accepted, is possible only through the pursuit and adherence to the principles of sustainable economic development. If we consider greening as a process, today it is more common to understand it as a process of gradual and consistent implementation of interconnected sound organizational, technological, technical, managerial and other solutions that help increase the efficiency of natural conditions and resources, while maintaining, and preferably b, improved the quality of the natural environment. In the context of the global 
environmental crisis, this can be defined as the main requirement of today. In the socioeconomic aspect, the basis of greening should be considered the transition to such methods and principles of management that would provide optimal resource use, and technically - the introduction of innovative eco-technologies of production and nature management [175].

Innovative theoretical developments in the direction of greening of modern production indicate the ways in which it should be implemented in practice. The greening movement, in turn, requires feedback from society in the form of not only theoretical agreement but also practical support for the transition to green production. According to some scientists, the solution of global environmental problems is associated with the transition to the bioeconomy as a new economic system. In particular, the development of biotechnology is often seen as one of the engines of environmentally sustainable production and the creation of a variety of innovative products that can mitigate or even solve some global problems of mankind.

Greening based on the use of living organisms in the production process is fully consistent with its essence. This applies, first of all, to such a branch of modern production as biotechnology, the development of which has been quite rapid recently. The use of new biotechnologies is primarily envisaged in such sectors of the economy as agriculture, medicine, pharmacology, chemical industry, and energy. In this case, these industries are considered as end producers of bioeconomy products Sustainable development of oilseeds production provides high yields without compromising natural resources and systems. Businesses that adopt this method of work and fully implement it, have more effective cooperation with the environment, do not ignore its needs and use the best of modern knowledge and technology, avoid the unpredictable consequences of industrial and chemical pollution. An important result of sustainable production is that businesses can minimize the use of pesticides, thus saving money and protecting future productivity and the environment, of course.

The oil and fat industry of Ukraine is characterized by a tendency to increase production, which is reflected in the environment. The generated fat-containing waste, getting into the environment, causes a negative impact, first of all, on the state of water 
sources. The grease contamination systems used in most oil and fat enterprises are inefficient and require the introduction of new technological solutions. Moreover, the oil production process itself requires a significant amount of water for oil production, the processes of chemical neutralization, subsequent washing and deodorization.

As the requirements for product quality and safety increase, it is important for every company that accepts the finished product to be able to track the entire production, processing and distribution so that if necessary to recall the product from the market, the seller could do it without error, in full and properly notify all other companies. The bidder must take all appropriate measures to ensure that the processed products can be traced at all stages. That is, there must be a register with relevant data on purchases, production and sales. The formation of an effective control system should be based primarily on the certification of the manufacturer and only then on the quality control of the products he produces. This practice is used in developed countries. Soils where raw materials are grown must be certified, as well as raw materials, equipment, technological equipment, personnel, vehicles, trade network and many other aspects of the enterprise. Thus, there is effective control throughout the chain from production to sale.

The issue of product quality of the enterprises of the oil and fat complex of Ukraine is one of the important problems of its development today. The peculiarity of the current system of state regulation of quality and safety of food products is the presence of several state institutions responsible for this direction; State Inspectorate of Ukraine for Consumer Protection; State Veterinary and Phytosanitary Service of Ukraine; State Sanitary and Epidemiological Service of Ukraine; Ukrainian Research and Training Center for Standardization, Certification and Quality, as well as a number of public organizations for the protection of protection.

For the harmonization of national standards in accordance with EU legislation in the field of safety and quality of food products in 2014. came into force in Ukraine conference Zakon "Pro osnovni principles ta ta vymohy till the bezpechnosti yakosti harchovyh produktiv" maye chto nA meti zabezpechennya vysokoho level zahystu interests spozhyvachiv, a takozh stvorennya prozoryh umov driving hospodarskoyi 
diyalnosti, increasing konkurentospromozh-nosti vitchyznyanoyi produktsiyi harchovoyi promyslovosti. The law provides for the introduction in Ukraine of the European model of the system of guaranteeing the safety and quality of food products, which is based on the procedures of the HACCP; clarification of terminology, types of offenses and adequacy of the measure of punishment; creation of a single controlling body in the field of food safety; abolition of permits and procedures that are absent in the EU; implementation of European principles of GMO regulation, especially in the part of registration of GMO sources, and not products made from them.

The implementation of procedures based on the principles of HACCP in the capacity of processing enterprises is an extremely important method, because without these principles it is impossible to ensure that the product is manufactured in compliance with all standards for product quality and safety. According to the author, no processing enterprise can operate without the HACCP system today. Almost all modern standards of the food safety system are created on the basis of HACCP: ISO 22000, FSSC 22000, BRC, IFS, Global Gap, SQF and others. HACCP (Hazard Analysis and Critical Control Points) is a quality control system. It makes it possible to identify threats and apply control measures throughout the production chain. The HACCP concept meets the requirements of the Codex Alimentarius Commission, established by the World Health Organization and the Food and Agriculture Authority of the United Nations, to bring together international food standards, regulations and codes to ensure fair trade. There are seven principles that formed the basis of the HACCP system and are mandatory when creating a system for a particular enterprise - a food producer [176].

The first principle is to conduct a thorough risk analysis. This is done through the process of assessing the significance of potentially dangerous factors at all stages of the life cycle of food products, controlled by the manufacturer. The probability of any risks is also assessed, and general preventive measures are taken to prevent, eliminate and minimize the identified hazards. The second principle is the definition of critical control points, as well as technological stages and procedures in which strict control makes it possible to prevent, prevent potential danger or through certain 
measures to eliminate the possibility of risks. The third principle is to set critical limits for each control point. Here, criteria are defined that show that the process is under control. The developers of the system form tolerances and limits, which must be adhered to so that the situation does not get out of control at critical control points.

The fourth principle is the establishment of procedures for monitoring critical control points. To do this, surveillance systems are installed at critical points, and various inspections are created through regular analysis, testing and other types of production supervision. The fifth principle concerns the development of corrective actions to be taken in cases where inspections and surveillance indicate that the situation may be out of, out of control or out of control. The sixth principle is the establishment of accounting procedures and record keeping, which fixes the necessary parameters. The documentation will be a clear indication that the production processes at critical points are under control, all deviations are corrected, and the developed HACCP system for this company as a whole functions effectively. The last, seventh, principle is the establishment of procedures for checking the set of documentation, which must be constantly maintained in working order, reflect all measures for the implementation, enforcement and compliance with all the principles of HACCP. In other words, this set of documents will reflect the fact of viability of the developed HACCP system for this enterprise - a food producer.

The main idea of HACCP is to focus on critical points. The system is a warning method and is used in the food industry as a guarantee of product safety. The primary advantage of this system is the guarantee of the quality of manufactured products, the assessment of all weaknesses in doing business, the possibility of leveling them, and thus increase profits. Other benefits include the following: - Optimization of control of production processes; - Reducing damage and increasing shelf life; - Increasing the stability of the product; - Reducing costs by reducing the volume of defective products; - Consolidation of market positions. The development of Ukraine's market economy and access to world markets should determine new priorities for the development of production. This is, firstly, increasing the competitiveness of manufactured products. And here we are not talking about a specific system, HACCP is one way to achieve 
this goal, and if you follow all the principles of the system, which were discussed above, the chances of improving the image are quite high. Secondly, an important stage is the transition from mining to processing. Third, the creation of a system for ensuring the safety of consumed products should be an equally important part of increasing competitiveness.

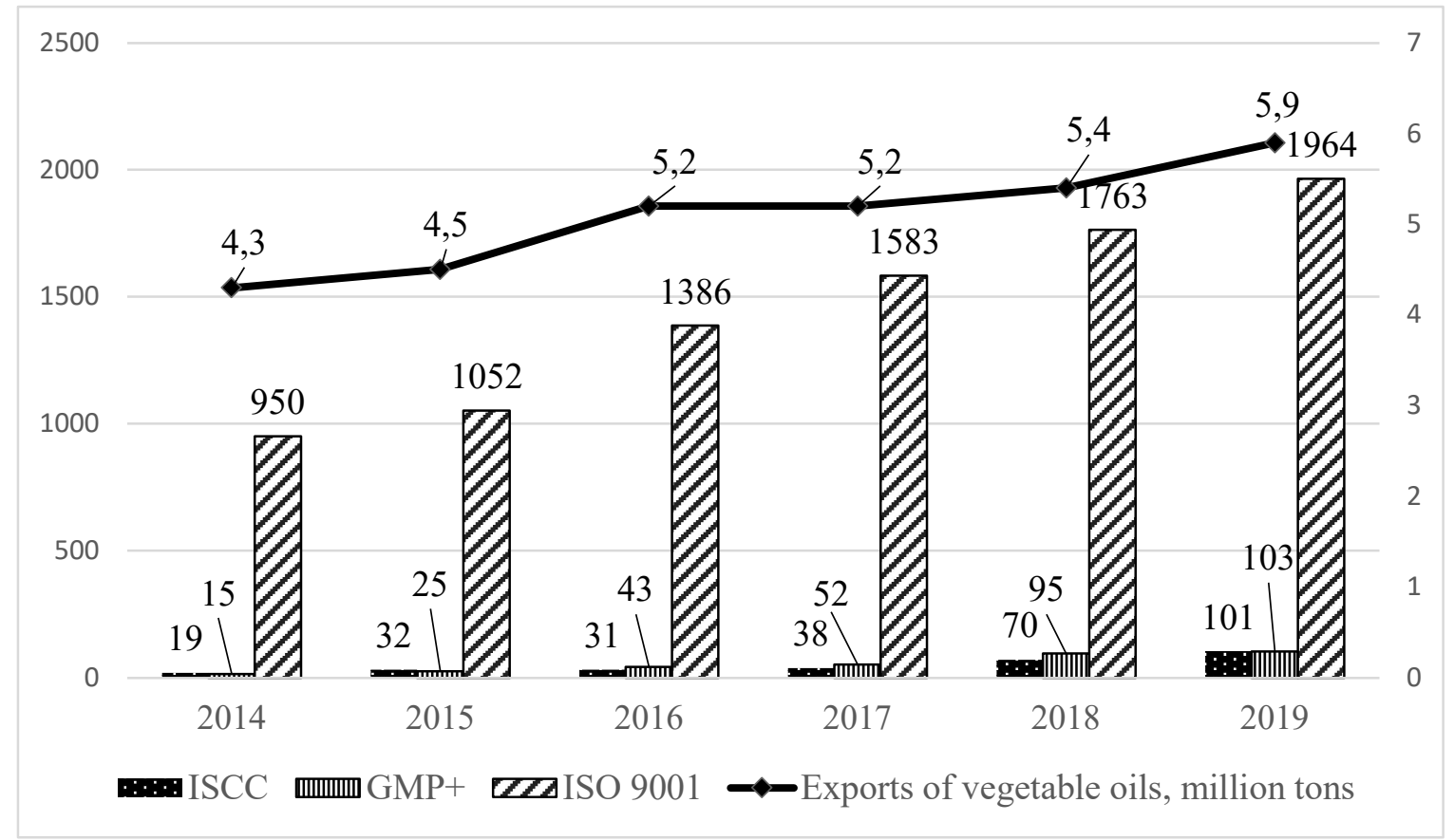

Fig. 5.2.2. Number of certificates and increase in vegetable oil exports to Ukraine in 20142019 Source: built by the author on the basis of [177].

Among the systems that have helped to increase and expand the range of exported products in recent years: ISCC for the export of rapeseed oil for biodiesel production, GMP + for the export of processed products for feed purposes, ISO 22000 to confirm food safety. ISO 9001 certification, an enterprise quality management system, helps to improve the company's image, and the processing companies themselves have the opportunity to increase the efficiency of production processes, as well as to achieve a stable result on an ongoing basis.

The introduction of international systems is the first step towards the greening of production, as they can neutralize biological, physical and chemical risks, reduce costs and increase competitiveness in both foreign and domestic markets. Businesses that have certificates of compliance with quality and food safety standards with 
international accreditation receive many competitive advantages. First, it is an opportunity to enter international markets where there are generally accepted world standards and trade rules. Secondly, it is an opportunity to participate in important tenders. Third, such companies have the opportunity to attract foreign investment, as an enterprise that has streamlined production processes and has a mechanism for analysis, control and improvement, and hence increase the efficiency of enterprise management. Fourth, obtaining the status of a reliable supplier that produces quality and safe product.

In addition to competitive advantages, companies also receive internal benefits that companies receive as a result of the introduction of the HACCP system: Management receives documented assurance about the safety of the product, which is especially important when analyzing complaints and possibly lawsuits. - Significant savings due to the reduction of the share of defective products, as preventive measures for the management of hazardous factors and the early warning system come to the fore, rather than delayed actions for already produced defective products. - Staff motivation increases, there is an opportunity to attract more qualified staff. Moreover, the company's plants are subject to GMP + B1 certification, trucking companies - GMP + B4, and transshipment facilities - GMP + B3. The laboratories of the enterprises are licensed according to the ISO 17025 standard, which allowed to expand the range of analyzes. The production of raw materials is also subject to certification. In particular, the cultivation and processing of corn is certified according to the ISCC EU standard. In addition, Kernel has been certified according to the EU ISCC standard for soybeans, rapeseed and wheat [178].

Given the factors of influence inherent in the oil and fat industry of our country, which characterize the state of the market of sunflower seeds and products of its processing, at all stages of a market economy, it is necessary to combine with a free pricing system and elements of government regulation. This principle should be used primarily to ensure price parity for agricultural products and means of production coming into this industry from industry. The state must have a realistic concept of prices, which would reflect the objective economic processes and limit the role of 
subjective factors in pricing. Given the possibility of industry development, prices for sunflower seeds should be set on the market under the law of supply and demand.

Analyzing the state and prospects of the oil and fat industry, it is safe to say that this industry has significant prospects in terms of providing the domestic market with quality and healthy products, and in terms of entering foreign markets a wider range of reliable products. The oil and fat industry has a number of problems, the main of which are: high level of concentration in the industry leads to loss of independence of smaller enterprises and leads to the disappearance of competition, monopoly in the industry, fluctuations in prices for both oil and oil; close dependence of the industry on the raw material base, which is affected by agriculture with seasonal, climatic problems; low quality of raw materials and oils that are exported leads to a decrease in export potential; insufficient use of energy-saving technologies; lack of state support. [179].

The expediency of greening the oil and fat industry should not be underestimated. First of all, all companies that are actively involved in improving the work through the introduction of energy-saving technologies are expanding the list of potential buyers. Second, such companies can be confident in the quality of their products and claim a higher price in the market. Third, the process of greening oil and fat enterprises will encourage business management to take the right approach in decision-making and to determine the vector of activities aimed at improving both the financial situation and the environmental and social component. Successful management decisions and effective control include the following: environmental performance assessment, environmental impact assessment, life cycle assessment, ecoaudit. 